Historic, Archive Document

Do not assume content reflects current scientific knowledge, policies, or practices. 



\section{Wholesale Price List of Gladioli}

Terms Cash with order unless credit is established. $25 \%$ deposit for deferred shipment. We shall try to put out true-to-name, disease-free young stock at the lowest price that first class stock can be grown.

BULBS-Price per 100 unless otherwise indicated.

By buying bulblets by count, hand picked you always get selected stock.

America, Soft flesh pink

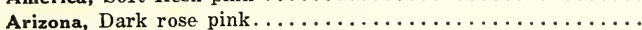

Chicago White, White, small markings.............

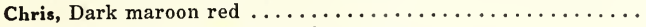

Conspicuous, Blue, pansy bloteh ................

Cracker Jack, Dark red, yellow and maroon blotch.........

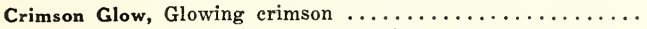

Czar Peter, Dark wine red, yellow stripes on lower petals....

Dawn, (Groff) Salmon pink, elaret strain in throat.........

E. J. Shaylor, Pure deep pink, ruffled. . . . . . . . .

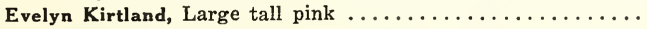

Flora, Pure golden yellow . . . . . . . . . . . . . .

Gen. Joffree, Bright scarlet . . . . . . . . . . . . . .

Glory of Kennemerland, Deep rose pink, ereamy yellow blotch

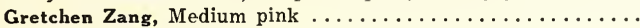

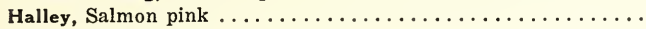

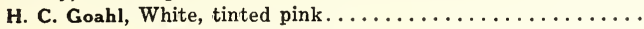

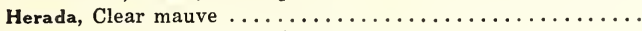

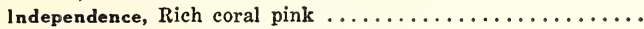

Jack London, Light salmon, vermillion stripes ..........

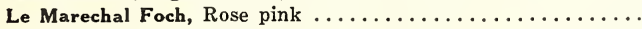

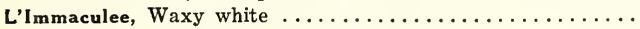

Mary Finnell, Light lavender, creamy throat . . . . . . . .

Mr. Mark, Lobelia violet $\ldots \ldots \ldots \ldots \ldots \ldots \ldots \ldots \ldots \ldots$

Mrs. Dr. Norton, Peach and eream color . . . . . . . . . .

Mrs. Frank Pendleton, Pink carmine bloteh . . . . . . . . .

Mrs. H. C. Bothin, Geranium pink, scarlet center, ruffled....

Mrs. Watt, Brilliant wine color . . . . . . . . . . . .

Muriel, Light blue with darker spots..............

Nebraska, Astor purple, yellow blotch . . . . . . . . . .

Neoga, Dark garnet $r e d . \ldots \ldots \ldots \ldots \ldots \ldots \ldots \ldots \ldots$

Niagara, Crocus yellow . . . . . . . . . . . . . . .

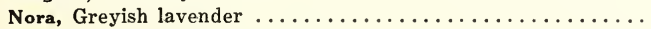

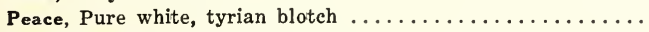

Pink Wonder, La France pink . . . . . . . . . . . .

Princely, Extra large white, GRAND!- (each) ......... (One of Kemp's Introduction)

Prince of Wales, Strawberry pink..............

Rosella, Light rose, lighter throat ................

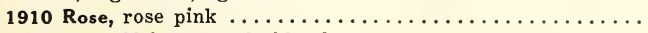

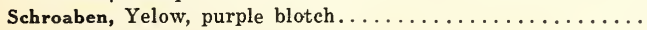

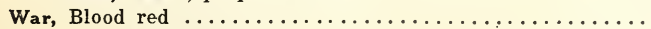

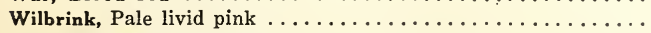

Willy Wigman, Rose, blending dark red bloteh..........

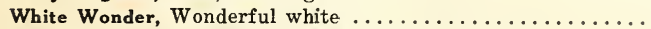

Wolverine, Coral pink, mottled tyran rose .............

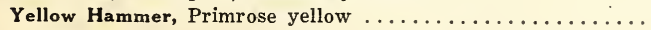

Primulinus, Hybrids, Kundered $11 / 4 " \underset{\$ p .}{\text { Up. }} 1 "-11 / 4 " 3 / 4 "$

2.00

1.50

$\ldots \ldots$

$\ldots \ldots$

5.00

2.50

.....

$\ldots \ldots$

.....

3.00

.....

$\ldots \ldots$

2.00

3.00

3.00

.....

1.75

3.50

3.50

....

2.50

$\ldots \ldots$

3.00

.....

$\ldots$.

2.50

....

$\ldots \ldots$

$\ldots \ldots$

....

......

$\ldots \ldots$

2.00

3.50

2.50

.....

$\ldots .$.

.....

2.00

1.50

1.50

1.00

$\ldots .$.

. $\ldots$.

$\ldots \ldots$

2.00

.....

.....

$\ldots$

2.00

2.00

$\ldots$

1.50

1.25

.....

2.00

.....

.....

1.00

2.00

2.50

.....

.....

2.00

.....

2.50

$\ldots \ldots$

$\ldots \ldots$

$\ldots \ldots$

1.75

.....

$\ldots \ldots$

$\ldots .$.

.50

$\ldots \ldots$

.....

1.50

2.50

2.00

$\ldots .$.

$\ldots \ldots$

$\ldots \ldots$

1.75

1.00

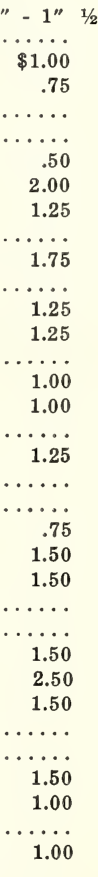

Bulblets " 3/4" Under $1 / 2$ " per 1000 $\$ .50$

$\$ .50$

$\$ .30$

.50

1.25

.....

.30

1.50

.75

$\ldots \ldots$

1.25

….

.75

$\ldots \ldots$

.50

.....

.75

....

.....

.50

......

1.25

.....

1.00

.....

....

1.25 । 0

1.00

.50

.75

.50

1.25

.75

.....

.25

1.00

.50

.....

$\$ .75$

.50

.50

1.25

.50

1.25

.75

2.00

2.00

1.00

.50

.50

.35

1.00

1.00

1.00

.75

1.00

.50

1.25

.50

.50

1.50

.50

1.00

1.00

1.00

1.00

1.75

.75
.75

....

1.00

1.00

1.00

1.00

.75

1.00

.50

.75

2.00

25.00

o.15

.75

.75

.75

.75

.75

.50

.50

1.00

.....

$\ldots .$.

.....

1.00

.60

2.00

1.00

.50

.50

.50

.50 
